\title{
In Diversity We Trust: The Positive Effect of Ethnic Diversity on Outgroup Trust
}

\author{
Birte Gundelach
}

Published online: 31 January 2013

(C) Springer Science+Business Media New York 2013

\begin{abstract}
Most studies on ethnic diversity and social trust rely on the standard measure of generalized trust. This study complements existing work on this topic by examining the effect of diversity on trust toward outgroups. This innovation is motivated by two closely connected arguments: At first, most existent studies are conducted in the framework of intergroup contact and conflict theory. These theories directly allude to trust toward outgroups. Second, recent empirical studies show that the standard measure of generalized trust is much less generalized than theoretically assumed. Instead it is blurred by a great deal of particularized trust. Explicit outgroup trust therefore seems to be better suited to empirically testing the extent to which growing ethnic diversity influences trust toward people different from oneself. The cross-national analysis yields a positive relationship between diversity and outgroup trust, which is an interesting finding given the current debate dominated by conflict theoretical reasoning.
\end{abstract}

Keywords Ethnic diversity - Generalized trust - Outgroup trust - Contact theory · Conflict theory

\section{Introduction}

Previous research on the impact of ethnic diversity on social trust almost exclusively focuses on one specific form of trust, namely generalized trust (Marschall and Stolle 2004; Anderson and Paskeviciute 2006; Bjørnskov 2008; Gesthuizen et al. 2008; Hooghe et al. 2009; Tolsma et al. 2009; Gijsberts et al. 2012). In contrast to particularized trust, which is trust at close social range and referring to people one knows from everyday interactions, generalized trust is a rather abstract attitude

B. Gundelach ( $\square)$

Institute of Political Science, University of Bern, Lerchenweg 36, 3012 Bern, Switzerland

e-mail: birte.gundelach@ipw.unibe.ch 
toward people in general, encompassing unknown strangers about whom no information exists. The benefits that social capital theory ascribes to widely shared trust in a given community are assumed to be gained mainly from this generalized form of trust (Fukuyama 1995). Regarding its pivotal function in modern societies, the weakening of generalized trust in ethnically diverse societies has rightly been an important research topic in the last decade (Sturgis et al. 2011).

In this paper I argue that existent evidence from diversity and generalized trust should be complemented by a focus on explicit outgroup trust. Outgroup trust means trust across cultural identities, i.e. trust in people with whom one does not share and recognize a common group identity. As explained below, there are both theoretical as well as empirical considerations motivating this kind of innovation.

In order to theoretically connect ethnic diversity and trust, the literature mainly uses three different hypotheses. The first is the contact hypothesis, which predicts that ethnic diversity ameliorates intergroup relationships through continuous intercultural contact. Secondly, there is the conflict hypothesis, which expects that ethnically heterogeneous contexts lead to negative attitudes toward outgroups evoked by ethnic group competition over economic resources and cultural domination. And last, we have constrict theory, a reformulation of conflict theory offered by Putnam (2007), stating that "[d]iversity seems to trigger not in-group/ out-group division, but anomie or social isolation" (p. 149). While it seems plausible to use generalized trust in order to test the general idea of the constrict hypothesis, testing this relationship in the framework of intergroup contact and conflict theory suggests a focus on diversity's effect on explicit outgroup trust. Obviously, conflict theory predicts the deterioration of attitudes toward outgroups and contact theory refers to the enhancement of attitudes toward outgroups.

Closely connected to this theoretical argument, there are empirical considerations that give reason to complement existent evidence with a focus on outgroup trust. Although some authors argue that generalized trust should implicate trust toward outgroups (e.g. Uslaner 2002; Stolle 2002; Delhey et al. 2011; Torpe and Lolle 2011), a growing number of recent methodological studies show that the standard generalized trust question often does not measure this abstract notion of "people in general" including unknown strangers and outgroup-members (Sturgis and Smith 2010; Torpe and Lolle 2011). Instead, survey measures of generalized trust are highly blurred by particularized trust, because survey respondents base their responses too often on people they know or meet in their daily life, and think first of people like themselves when asked this question. This observation reinforces the

Table 1 Outgroup trust among "generalized trusters" (row percent)

\begin{tabular}{llllll}
\hline & $\begin{array}{l}\text { No trust } \\
\text { at all }\end{array}$ & $\begin{array}{l}\text { Trust not very } \\
\text { much }\end{array}$ & $\begin{array}{l}\text { Trust } \\
\text { somewhat }\end{array}$ & $\begin{array}{l}\text { Trust } \\
\text { completely }\end{array}$ & $N=100 \%$ \\
\hline $\begin{array}{l}\text { Trust in people with another } \\
\text { nationality }\end{array}$ & 11 & 29 & 51 & 9 & 15.632 \\
$\begin{array}{l}\text { Trust in people with another } \\
\text { religion }\end{array}$ & 9 & 28 & 53 & 9 & 15.668 \\
\hline
\end{tabular}

Source World Values Survey 2005-2008, 47 countries 
notion that generalized trust is not suitable to test intergroup theory in its original sense.

A look at Table 1, which displays the relationship between generalized trust and trust toward outgroups based on World Values Survey data, further substantiates this fact: We observe that 10 out of 100 respondents stating that "most people can be trusted" decline to trust people with another religion or nationality "at all". About a third of supposed generalized trusters indicate to trust outgroups "not very much". Only $60 \%$ of the nominal social trusters, then, trust outgroups "completely" or "somewhat". Especially in countries outside of the "western" world, generalized trust measures a trusting attitude much less inclusive than theoretically assumed by various scholars (see also Delhey et al. 2011; Torpe and Lolle 2011).

With the intention to test the relationship between diversity and social trust in the theoretical framework of intergroup contact and conflict theory, I argue that it is interesting and important to supplement existent research on diversity and trust by a differentiated perspective on explicit outgroups trust.

Surprisingly, almost none of the follow-up studies of Putnam's seminal article, "E pluribus unum" (2007), focus explicitly on the impact of ethnic diversity on trust toward outgroups (e.g. Gesthuizen et al. 2008; Hooghe et al. 2009; Sturgis et al. 2011; Laurence 2011; Öberg et al. 2011, but see Rudolph and Popp 2010, who reanalyze the data used by Putnam 2007). This is probably due to the problem of data availability. While data on explicit outgroup trust still remains less available than generalized trust, the latest World Values Survey (WVS) now offers data on this specific form of trust.

The present paper makes use of these new trust items and offers the first crossnational analysis of the impact of ethnic diversity on outgroup trust. In order to compare the models on explicit outgroup trust with the established approach, we also show the effect of ethnic diversity on generalized trust. The differentiated perspective on trust toward outgroups presented here strengthens contact theory, which is an interesting finding given the current academic and public debate dominated by conflict theoretical reasoning. The findings furthermore show that the positive effect of diversity is strongest in countries where ethnic diversity is a longstanding and familiar feature of society. The effect fades in countries where ethnic diversity is induced by more recent immigration during the last few decades.

The remainder of the article proceeds in four main sections: the following section briefly introduces the basic insights of intergroup theory. Section 3 describes the data and the methodological approach for the empirical analysis. The subsequent section presents and discusses the empirical results. The last section summarizes central findings and offers some conclusions.

\section{Social Trust in Heterogeneous Societies}

Most of the previous research dedicated to diversity and trust cite intergroup contact and conflict theory to theorize about the relationship between diversity and trust (e.g. Stolle et al. 2008; Letki 2008; Lancee and Dronkers 2011). In fact, original accounts of intergroup theory only implicitly mention the impact of ethnic diversity 
and minority concentration on social trust. In borrowing insights from the literature on social context and ethnic prejudices or racial attitudes toward outgroups, however, research on social trust adapts intergroup theory in order to explain the potential causal mechanism between cultural heterogeneity and social trust. In general, trust can be described as the expectation that others will contribute to the well-being of a person or a group, or at least that they will refrain from harmful actions (Offe 1999; Freitag and Traunmüller 2009). In line with "ethnic prejudice" and "racial attitudes," social trust is also perceived as an "affective orientation toward others" (Rudolph and Popp 2010, p. 75). Social trust research thus assumes that the causal mechanism involved in the formation of ethnic prejudice and racial attitudes has similar implications for the development of social trust.

The following paragraphs summarize the most important tenets of intergroup theory in order to introduce the theoretical discussion behind these famous hypotheses, and more importantly to underline the suggestion to use explicit outgroup instead of generalized trust to test the hypotheses derived from intergroup theory empirically.

\section{Contact Theory}

Contact theorists assume that repeated and continuous encounters with outgroup members in varied settings result in a learning process about the outgroup, which in turn corrects negative views of the outgroup and reduces prejudice (Allport 1954; Pettigrew 1998). In addition to these cognitive processes, emotion and empathy play critical roles in intergroup contact. Most important are positive emotions caused by intercultural friendship (Cook 1962). As social relations and patterns of social interaction are structured by the composition of their respective social environment, pronounced ethnic diversity should involve increased prospects and opportunities for mutual exposure to different groups, which in turn leads to enhancement of intergroup relationships (Huckfeldt 1986; Blau 1977). Previous studies show that diversity in fact leads to more frequent interethnic contacts, with a corresponding beneficial effect on intergroup relationships (Wagner et al. 2006; Schlueter and Wagner 2008; Schlueter and Scheepers 2010). In addition, the presence and visibility of people from different cultural backgrounds in the media, art and public institutions should lead gradually to familiarity with the unknown other, developing trust toward outgroups over time.

Hypothesis 1 Ethnic diversity strengthens outgroup trust.

\section{Conflict Theory}

We generally can accept that the "homophily principle" plays a major role in the organization of social life: that is, human beings prefer the familiar (McPherson et al. 2001). This assertion by itself does not imply competitive or even conflictive intergroup relations; it does, however, suggest that groups of people arrange themselves by specific salient group memberships and are, at the very least, wary of 
other individuals and groups who seem to look, act, or think differently from themselves (Uslaner 2002).

Taking a closer look at the literature on ethnic prejudice and intergroup hostility, at least two perspectives can be distinguished. First, ethnic prejudice and hostility towards outgroup members is understood as a personal phenomenon that becomes particularly salient in ethnically heterogeneous contexts (Allport 1954). One detail of the explanation of intergroup hostility and mistrust in culturally diverse societies is thus the claim that negative orientations toward outgroups are ultimately natural human propensities that are especially prevalent in heterogeneous societies, where culturally different groups interact in numerous situations. Rather than being driven by rationality, these social-psychological approaches assume the affective expressions toward outgroups largely to be beyond complete conscious control (Quillian 1995). Second, intergroup animosity is understood as a genuine societal group phenomenon (Blumer 1958). It is assumed that multicultural settings lead to intergroup conflict and mistrust evoked by intergroup competition over economic resources, political power and cultural dominance.

Hypothesis 2 Ethnic diversity weakens outgroup trust.

Previous research furthermore suggests that studies on the effects of diversity should distinguish two kinds of ethnic diversity that might influence individual attitudes differently (Hooghe et al. 2009; Gesthuizen et al. 2008). Diversity may first be understood as a traditional and longstanding property of societies where ethnic minorities have been members of their community for a very long time. The second form of diversity would be a more recent phenomenon that has emerged out of rather rapid immigration in the last few decades. Following the logic of intergroup theory, diversity induced by more recent and rapid immigration should evoke more anxiety and perceived threats based on competition over resources, power and values in contrast to diversity that presents as a long-standing feature of the respective society (Huddy et al. 2005; Hooghe et al. 2009). In the latter case, intergroup contact may already have had substantive positive impacts on attitudes toward outgroups, because different cultural groups have already lived for long periods in familiar co-existence (Forbes and Hugh 1997).

\section{Data and Methods}

To analyze the effect of ethnic diversity on outgroup trust cross-nationally, the fourth wave of the WVS (2005-2008) was used for individual-level data. In contrast to previous studies that use generalized trust as dependent variable, I make use of the newly introduced measures of explicit outgroup trust. As outlined above, it is argued that this approach is better able to address the theoretical predictions derived from intergroup conflict and contact theory instead of examining the effects on generalized trust. In addition, this approach accounts for the criticism of the empirically quite narrow radius of trust in the standard measurement of generalized trust. The items on trusting people of another religion and trusting people of another nationality are used as indicators for outgroup trust, referring to trust in people with 
whom one does not share a common group identity (Delhey et al. 2011). The wording of the questions is as follows: "I'd like to ask you how much you trust people from various groups. Could you tell me for each whether you trust people from this group completely, somewhat, not very much or not at all?"1

In accordance with previous research on this topic, the most commonly used measure for aggregate ethnic diversity, the Herfindahl fractionalization index, is used in the empirical test. The index is computed as: $H I=1-\sum_{i=1}^{N} s_{i}^{2}$ where $N$ is the number of characteristic values considered (i.e. number of ethnic groups), $s_{i}$ is the fraction of individuals with characteristic value $i$ in the population. The index ranges from 0 to 1 . It can be understood as the probability that two randomly chosen individuals in a country are different with regard to the considered characteristic value. The analysis relies on cross-national diversity data provided by Fearon (2003). In order to test if and how the relationship between diversity and trust depends on the nature of diversity (diversity predominantly induced by recent immigration versus diversity as a long standing feature of society) I use two different variables to interact with diversity: the share of migrants in a country as well as the development of the share of migrants. ${ }^{2}$

To avoid spurious relationships, several controls at both the individual and contextual level of analysis are considered. With regard to the selection of control variables, I rely on insights gained from previous research on the determinants of social trust (Freitag and Traunmüller 2009). In addition to socio-demographic variables, I control for individual resources: as is widely-known, greater resources in terms of education and income, as well as social resources, such as active organizational membership in civic organizations, are correlated with more trusting behaviors. Previous research has also shown that optimism and a sense of control are important predictors of social trust (Uslaner 2002, 2012). Therefore, the models include a measurement of a respondent's happiness as a proxy for these predictors.

Of even greater importance for the analysis is the introduction of alternative explanatory variables at the contextual level of analysis. Various studies on the determinants of social trust document that economic inequality is specifically detrimental to social trust (Bjørnskov 2008; Uslaner and Brown 2005). Furthermore, economically prosperous societies also tend to be more trusting societies. For details on operationalization, coding, sources, and summary statistics, see the appendix.

The problem of missing data was approached by means of multiple imputation (King et al. 2001) using Stata 12. In multiple imputation, one imputes $m$ values for each missing cell in the data matrix and creates $m$ completed data sets. I imputed missing values using chained equations and imputed a total of 10 data sets. Across

\footnotetext{
1 The reader should be aware of the fact that the items "trust in another nationality" and "trust in another religion" as indicators of outgroup trust bear the risk of being not equivalently understood by individuals across cultural contexts. In other words, as is the case with many other attitudinal measures in crossnational research, we cannot be ultimately sure that cross-cultural measurement equivalence can be guaranteed (but see Freitag and Bauer 2013). Nevertheless, these indicators are currently the best indicators available for cross-national research.

${ }^{2}$ For several countries of the former Eastern Bloc, there were no data on migration before 1990. Therefore, the period 1990-2005 was chosen to calculate the development of the share of migrants.
} 
these completed data sets, the observed values are the same, but the missing values are filled in with different imputations that reflect the uncertainty about the missing data. Values for each country were imputed separately in order to account for the clustering of the data. After imputation, each data set was analyzed separately and the results were then combined by applying Rubin's combination rules (Rubin 1987).

The hierarchical structure of both the theory and data calls for multilevel analysis: we study the impact of contextual ethnic diversity on individual trust toward outgroups. Given the distribution of the dependent variable, one useful model would be the multilevel ordered logit model. Confronted with a large dataset with roughly 70,000 individuals nested in 47 countries and 10 multiply imputed datasets created to handle missing values with state-of-the-art procedures, unacceptably long convergence times were the result, even for the baseline model. I therefore decided to follow an alternative approach to model the ordered categorical data (see Snijders et al. 2012, Gelman and Hill 2007). I dichotomized the ordered categories and analyzed the dichotomizations of the outgroup trust variables separately. In addition to being easier to fit, these models share the advantage of being more straightforward to interpret by most readers. As will be shown in the next section, both forms of dichotomization lead to similar conclusions with regard to the interesting relationship between diversity and trust. Thus I suggest that the logistic models are a suitable alternative to the ordered logit model for the data at hand (Snijders et al. 2012).

47 countries out of the WVS sample were included in the analysis. A number of countries in the WVS had to be dropped due to missing important variables in their country surveys. ${ }^{3}$ In adherence to a model-based approach, we did not use weights in the presented models.

\section{Empirical Results}

Table 2 displays the model estimates for generalized trust as well as for the outgroup trust items. As mentioned in the method section, I handle the multicategory data for outgroup trust by dichotomizing both outgroup trust variables. In order to show that the chosen dichotomization point does not influence the results substantively, I display separate binary logistic regression analyses using two plausible alternative dichotomizations of outgroup trust. Taking account of the ordering of the trust categories, I use cumulative probabilities to recode the trust variables. In the first variant outgroup trust is dichotomized as "at least trusting

\footnotetext{
3 For Japan, Iraq, Guatemala, Hong Kong, Iran, and New Zealand there were no differentiated trust questions available. Missing data on GDP and individual income prevent the inclusion of Taiwan, Andorra, Argentina, and Jordan. The following countries thus are included in the analysis: Australia, Brazil, Bulgaria, Burkina Faso, Canada, Chile, China, Colombia, Cyprus, Egypt, Ethiopia, Finland, France, Georgia, Germany, Great Britain, Ghana, India, Indonesia, Italy, Malaysia, Mali, Mexico, Moldova, Morocco, Netherlands, Norway, Peru, Poland, Romania, Russia, Rwanda, South Africa, South Korea, Serbia, Slovenia, Spain, Sweden, Switzerland, Thailand, Trinidad, Turkey, Ukraine, Uruguay, United States of America, Vietnam, and Zambia.
} 


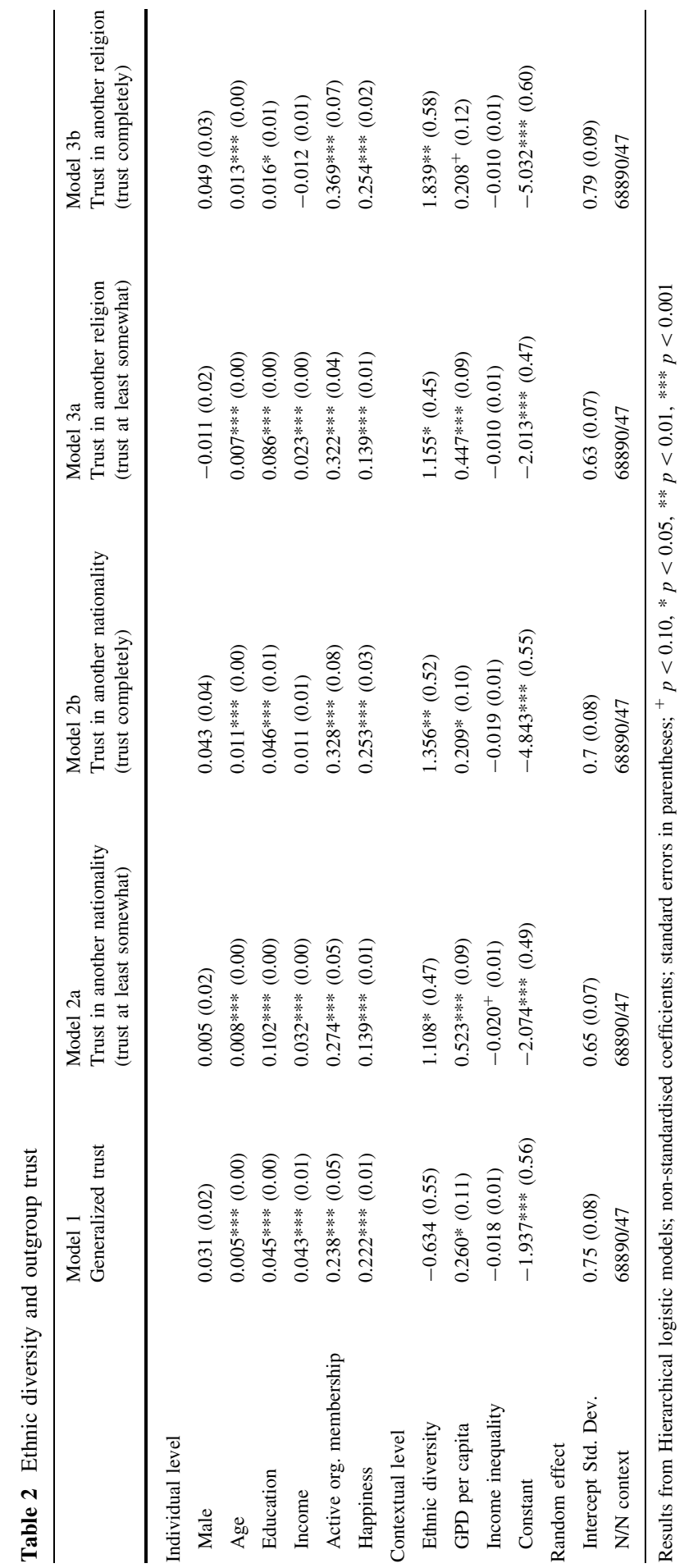


somewhat" with the following two categories: $1=$ "trusting completely", "trusting somewhat" versus $0=$ "trusting not very much", "trusting not at all", (Model 2a and 3a). The second variant dichotomizes outgroup trust as "trust completely", again with two categories, namely $1=$ "trusting completely" versus $0=$ "trusting somewhat", "trusting not very much", "trusting not at all" (Model 2b and 3b).

In order to compare the presented models of the effect of diversity on explicit outgroup trust with the established approach, model 1 shows the effect of ethnic diversity on generalized trust, the standard analysis in previous cross-national studies (e.g. Anderson and Paskeviciute 2006; Bjørnskov 2008; Hooghe et al. 2009). As can be seen, the effect of ethnic diversity on generalized trust tends to be negative; it does not, however, reach statistical significance. Turning to the relationship between diversity and outgroup trust, the inference to be made changes. Controlling for individual determinants as well as the economic conditions in a country, we observe that individuals in ethnically heterogeneous societies exhibit more outgroup trust than those who live in culturally more homogeneous settings. This positive relationship between diversity and trust is observed for both indicators of outgroup trust as well as for both alternative dichotomizations of the outgroup trust variables.

Clearly, these empirical results run counter to the predictions expected from conflict theory and thereby also diverge from previous findings that show a negative link between trust and diversity using generalized trust (Anderson and Paskeviciute 2006; Stolle et al. 2008; Delhey and Newton 2005), or no consistent relationship at all (Bjørnskov 2008; Gesthuizen et al. 2008; Hooghe et al. 2009). Rather, in line with expectations derived from contact theory, individuals in social contexts characterized by ethnic diversity are more likely to trust outgroups than individuals in ethnically more homogeneous contexts. The data suggest that culturally diverse contexts offer increased opportunities for positive intercultural experiences and exchange, which in turn leads to increased social trust across different cultural groups. $^{4}$

Regarding individual control variables, there are only negligible differences across the models, and these results conform to previous research on diversity and (generalized) trust (see e.g. Sturgis et al. 2011): older and more educated individuals tend to be more trusting, as well as those who are civically engaged. Furthermore, general happiness impacts positively on outgroup trust (Uslaner 2002). Turning the attention to the context effects, we see that in economically prosperous countries, people tend to trust more than in countries with poorer economic conditions. These findings also conform to present research on social trust.

The present analysis can serve as a first indication that previous findings showing a negative correlation between diversity and generalized trust should perhaps be

\footnotetext{
${ }^{4}$ Further analyses show that the findings are robust to alternative model specifications and the exclusion of outliers (not shown). Neither the degree of liberal democracy nor the religious tradition of a country changes the results substantially (Bjørnskov 2008; Delhey and Newton 2005; Tsai et al. 2010; Delhey et al. 2011). Linear hierarchical modeling also yields a positive relationship between ethnic diversity and outgroup trust. The exclusion of potentially endogenous individual variables such as "happiness" or "active organizational membership" does not change the results either (not shown).
} 
viewed with more scrutiny and not easily be accepted as a corroboration of conflict theory. As argued above, conflict theory requires looking at outgroup trust (not generalized trust), and this differentiated perspective indeed leads to different empirical findings compared to analyses using generalized trust as dependent variable. This theoretical suggestion becomes even more important in the face of the recent criticism of the narrow trust radius of generalized trust. Consequently, it does not appear that outgroup trust - as implicitly assumed in some previous studiescan be held responsible for lower generalized trust attitudes in ethnically more diverse contexts (cf. Dinesen 2011; Gerritsen and Lubbers 2010; Bahry et al. 2005; Oliver and Wong 2003).

A caveat is in order with regard to the generalizability of the results. The WVS sample was selected for analysis because of the differentiated trust questions, which allow for a more adequate operationalization of the hypotheses derived from intergroup theory. In evaluating the present findings, we should be aware of the sample of countries that could be used in the present analysis (see footnote 3 ). The effect of ethnic diversity on trust is currently discussed mainly in the most developed countries that have attracted numerous immigrants in the last decades, thereby contributing to rapidly increasing diversity in these immigration countries (Gesthuizen et al. 2008; Hooghe et al. 2009; Putnam 2007; Rudolph and Popp 2010). The WVS sample, however, also includes a high number of less developed countries, as well as emerging economies where ethnic diversity is a long standing feature of society and not induced recently by immigration.

In a last step, we therefore test the extent to which the diversity effect depends on either a long standing and familiar, or rather dynamic and recent nature of ethnic diversity (cf. Hooghe et al. 2009; Tsai et al. 2010; Lolle and Torpe 2011). To test in how far the effect of diversity on outgroup trust is dependent on the character of diversity, I calculated interaction effects between diversity and two different indicators of immigration. I consider the share of migrants in a country as well as the development of the share of migrants. ${ }^{5}$ Because statistical as well as substantial significance of interaction effects is not necessarily observed from the presentation of the coefficients, Fig. 1 graphically depicts interaction effects between diversity and the share of migrants in a country as well as the development of the share of migrants (cf. Brambor et al. 2006). ${ }^{6}$ We see that the positive effect of diversity holds for countries where immigration is not an issue and where ethnic diversity is instead a stable and long-standing feature of society. The positive effect disappears, however, for countries with higher rates of immigration. In countries where heterogeneity has grown by relatively recent and rapid immigration, this positive effect of diversity on outgroup trust is no longer statistically significant. In sum, this brief analysis suggests that the relationship between diversity and outgroup trust is contingent upon whether the nature of ethnic diversity is static or dynamic.

All in all, the present analysis bears good news for the often pessimistic current debate on diversity and social trust. Indeed, ethnic diversity developed by recent

\footnotetext{
5 In order to save space only the effects of "trust at least somewhat" are provided. Results however do not differ in any substantive way when instead "trust completely" is used as the response variable.

${ }^{6}$ Consider Table 3 in the appendix for the coefficients of the model estimates.
} 

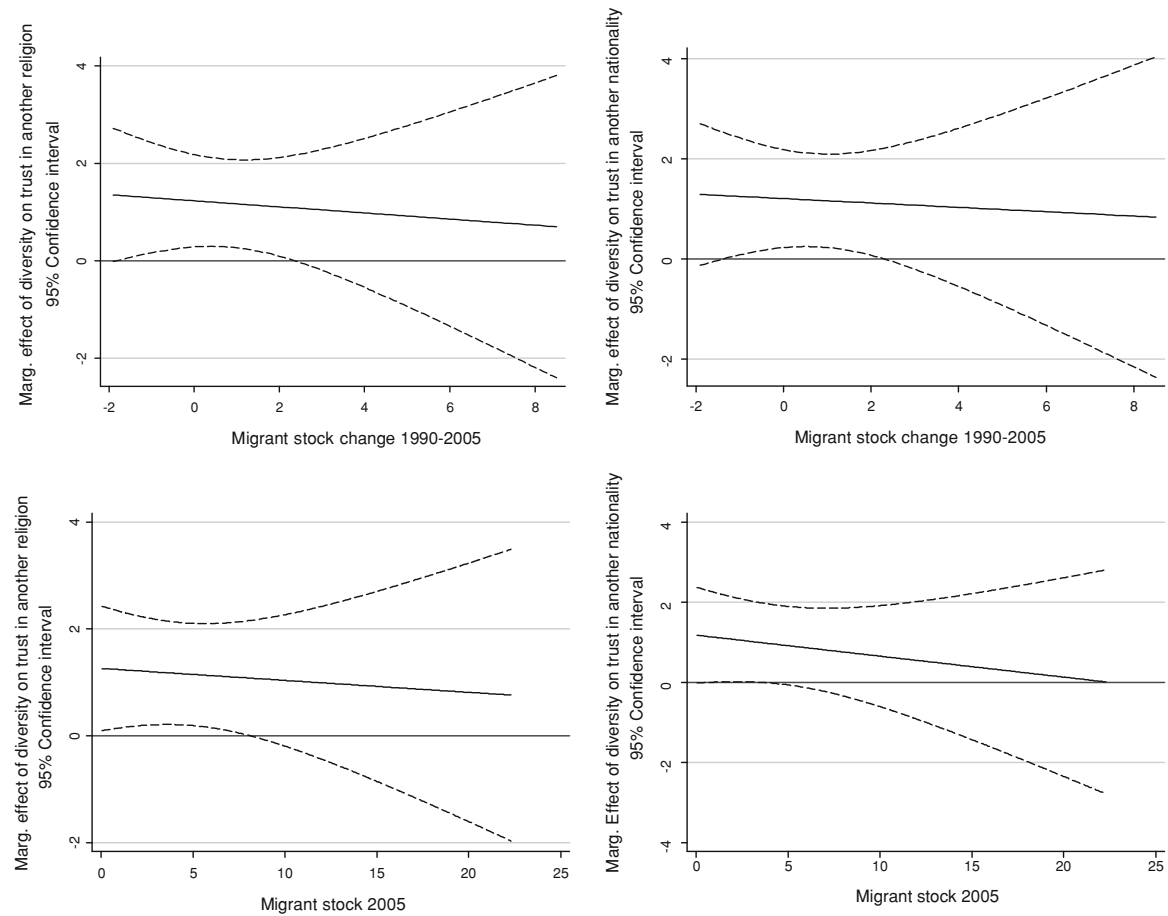

Fig. 1 Marginal effects of ethnic diversity on out-group trust (trust in another religion, trust in another nationality) as stock of migrants/development of stock of migrants changes. For coefficients of these interaction effect models see Table 3 in the appendix

(and fast) immigration seems to be less able to foster mutual trust across different cultural groups (and may even have negative effects on trust). Nevertheless, ethnic diversity, over the long run, seems to have the capacity to strengthen trust toward outgroups, as assumed by the contact theory.

\section{Conclusion}

This study contributes to the ongoing controversy regarding the relationship between ethnic diversity and social trust. In contrast to previous studies on this highly debated topic, this paper examines the effect of ethnic diversity on out-group trust-and not generalized trust. This particular approach is relevant for at least two closely connected reasons.

First, existing research on diversity and trust often uses the framework of intergroup contact and conflict theory. Although these theories definitely imply hypotheses on the effects of outgroup trust, hardly any of previous studies test the diversity effect on outgroup trust as explicitly suggested by these theories. Although analyzing the effect of diversity on generalized trust is interesting in its own right, generalized trust is less suitable to test the effects of diversity on outgroup trust. To approximate outgroup trust by using generalized trust is only an acceptable strategy 
insofar as we can assume that generalized trust measures include trust in people different from ourselves, i.e. trust in people with different social and cultural group memberships. This point directly leads to the second motivation to focus on outgroup trust.

Recent studies (as well as the present study) have precisely shown that empirically, the standard measure for generalized trust is much less generalized than theoretically assumed (Sturgis and Smith 2010; Delhey et al. 2011; Torpe and Lolle 2011). Instead it entails a great deal of particularized trust and a particular lack of trust toward individuals with an obvious different social or cultural identity.

Given the theoretical suggestion to focus on explicit outgroup trust, and the recent criticism of the factually too narrow trust radius of generalized trust measures, this paper complements the research on diversity and trust with a differentiated perspective on outgroup trust.

In contrast to previous cross national analyses examining the diversity effect on generalized trust that found generalized trust to be damaged or not affected at all, the differentiated perspective on outgroup trust yields a positive relationship between ethnic diversity and outgroup trust (Anderson and Paskeviciute 2006; Stolle et al. 2008; Delhey and Newton 2005; Bjørnskov 2008; Gesthuizen et al. 2008; Hooghe et al. 2009). The WVS data can thus be seen as promising with regard to social cooperation in heterogeneous contexts-intergroup contact being the potential force behind the presented findings. In ethnically more heterogeneous societies, people tend to trust outgroup members more than in homogeneous countries. Considering contact theoretical implications, the findings suggest that ethnic diversity offers increased contact opportunities and positive intercultural exchange across different kinds of cultural groups, that-when effectively usedlead to mutual understanding and trust.

After differentiating further between a dynamic and static nature of ethnic diversity, the analysis suggests that the positive effect of ethnic diversity on outgroup trust is strongest in countries where ethnic diversity is a rather stable national characteristic. We observe, however, no such (statistically significant) positive effect in the most prosperous and developed societies where fast-growing diversity due to immigration in the last decades is a vital and contested issue in national public debates.

In the short term, ethnic diversity generated by recent and rapid immigration may not foster trust across different cultural groups, as argued by contact theorists (and might even have deteriorating effects on social trust). In the long run, however, ethnic diversity seems to have the potential to breed trust across different cultural groups.

Acknowledgments This article has benefited greatly from the comments and suggestions offered by Markus Freitag, the editors, and three anonymous reviewers. I wish to also thank Jennifer Shore and Wesley Dopkins for their linguistic assistance.

\section{Appendix}

See Tables 3, 4, 5, 6 and 7 . 


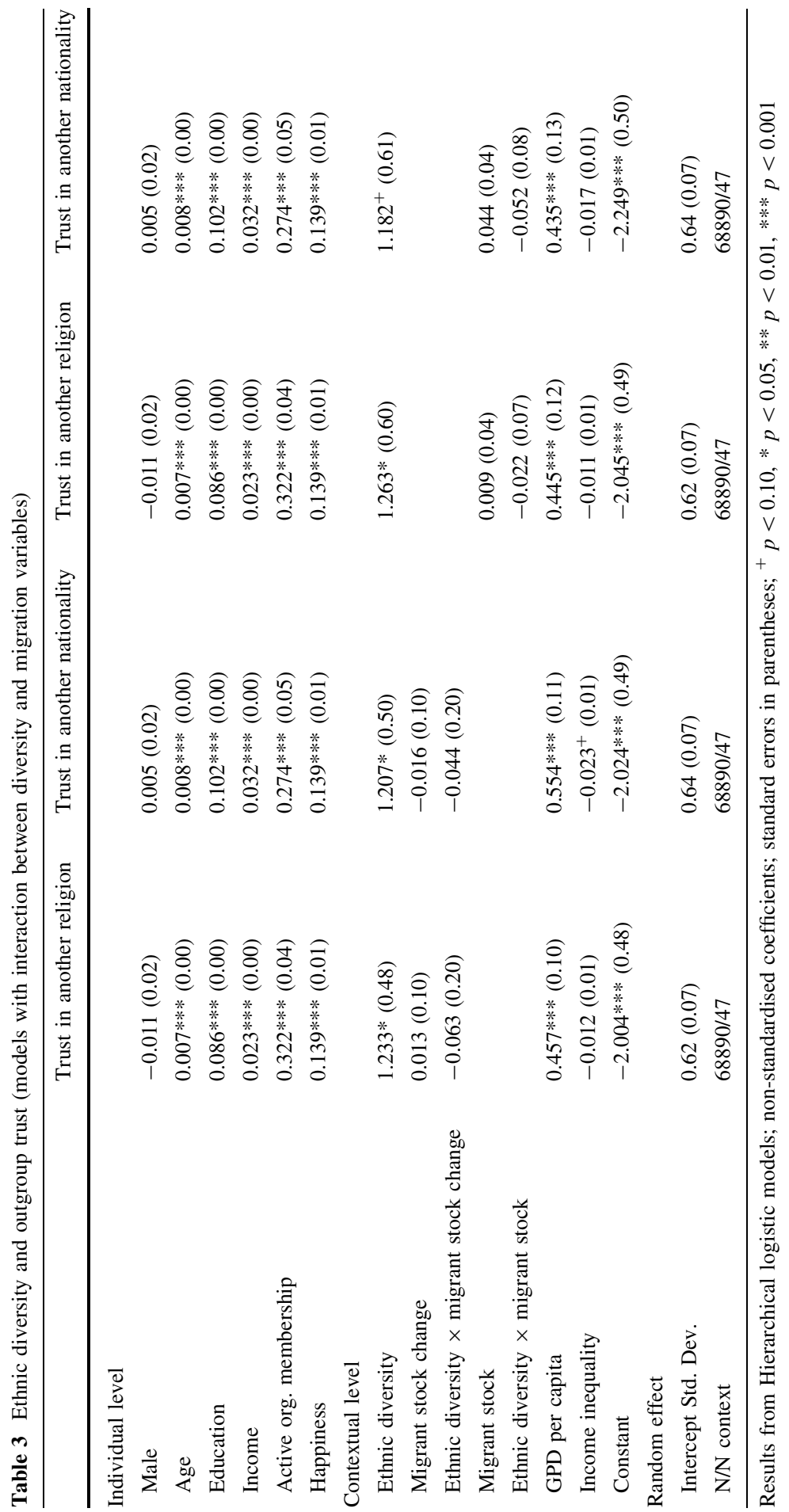


Table 4 Summary statistics

\begin{tabular}{|c|c|c|c|c|c|}
\hline Variable & Mean & Std. Deviation & Min & $\operatorname{Max}$ & Observations \\
\hline \multicolumn{6}{|l|}{ Individuals } \\
\hline Generalized trust & 0.26 & 0.44 & 0 & 1 & 66,054 \\
\hline Trust nationality & 2.27 & 0.85 & 1 & 4 & 63,420 \\
\hline Trust religion & 2.38 & 0.83 & 1 & 4 & 63,664 \\
\hline Sex & 0.48 & 0.50 & 0 & 1 & 68,844 \\
\hline Age & 41.79 & 16.64 & 15 & 98 & 68,671 \\
\hline Education & 5.19 & 2.50 & 1 & 9 & 68,397 \\
\hline Income & 4.58 & 2.32 & 1 & 10 & 63,385 \\
\hline Ass. membership & 0.04 & 0.19 & 0 & 1 & 68,527 \\
\hline Happiness & 3.09 & 0.73 & 1 & 4 & 68,176 \\
\hline \multicolumn{6}{|l|}{ Context } \\
\hline Ethnic diversity & 0.45 & 0.25 & 0.004 & 0.88 & 47 \\
\hline Gini-index & 39.40 & 10.16 & 25 & 59.3 & 47 \\
\hline GDP & 11645 & 11187 & 507 & 38165 & 47 \\
\hline Polity score & 6.20 & 5.27 & -7 & 10 & 47 \\
\hline Relig. Tradtion & 0.11 & 0.31 & 0 & 1 & 47 \\
\hline$\%$ Migrants & 5.42 & 6.00 & 0.05 & 22.32 & 47 \\
\hline Migrant stock change & 1.04 & 2.33 & -1.91 & 8.48 & 47 \\
\hline
\end{tabular}

Source World Values Survey 2005-2008, 47 countries

Table 5 Correlation individual variables

\begin{tabular}{|c|c|c|c|c|c|c|}
\hline Gen. trust & Trust nat. & $\begin{array}{l}\text { Trust } \\
\text { rel. }\end{array}$ & Sex & Age & Education & Income \\
\hline
\end{tabular}

\begin{tabular}{|c|c|c|c|c|c|c|c|c|}
\hline Trust nationality & 0.22 & & & & & & & \\
\hline Trust religion & 0.18 & 0.71 & & & & & & \\
\hline Sex & 0.01 & 0.02 & 0.01 & & & & & \\
\hline Age & 0.08 & 0.09 & 0.06 & 0.01 & & & & \\
\hline Education & 0.11 & 0.15 & 0.09 & 0.06 & -0.20 & & & \\
\hline Income & 0.11 & 0.11 & 0.08 & 0.04 & -0.08 & 0.34 & & \\
\hline Ass. membership & 0.01 & 0.04 & 0.06 & -0.01 & 0.01 & 0.01 & 0.03 & \\
\hline Happiness & 0.09 & 0.09 & 0.10 & 0.00 & -0.08 & 0.11 & 0.19 & 0.06 \\
\hline
\end{tabular}

Data source World Values Survey 2005-2008 
Table 6 Correlation context variables

\begin{tabular}{lrrrlll}
\hline & Diversity & Gini & GDP & Polity score & Relig. Trad. & \% Migrants \\
\hline Gini-index & 0.48 & & & & & \\
GDP & -0.41 & -0.36 & & & & \\
Polity score & 0.17 & -0.03 & 0.52 & & & \\
Relig. Tradition & -0.35 & -0.36 & 0.59 & 0.25 & & \\
\% Migrant & -0.15 & -0.39 & 0.72 & 0.39 & 0.38 & 0.53 \\
\% Migrant Change & -0.21 & -0.39 & 0.52 & 0.18 & 0.35 & \\
\hline
\end{tabular}

Data source World Values Survey 2005-2008

Table 7 Operationalization and sources of variables

\begin{tabular}{|c|c|c|}
\hline Variables & Operationalization & Data Source \\
\hline \multicolumn{3}{|c|}{ Individual level (Variables taken from the World Values Survey 2005-2008) } \\
\hline Outgroup trust & $\begin{array}{l}\text { Trust in another religion, trust in another nationality. } \\
\text { I'd like to ask you how much you trust people from various } \\
\text { groups. Could you tell me for each whether you trust } \\
\text { people from this group completely, somewhat, not very } \\
\text { much or not at all? } \\
1 \text { "not at all" } \\
2 \text { "Trust not very much" } \\
3 \text { "somewhat" } \\
4 \text { "Trust completely" }\end{array}$ & \\
\hline Generalized trust & $\begin{array}{l}\text { Generally speaking, would you say that most people can be } \\
\text { trusted or that you need to be very careful in dealing with } \\
\text { people? } \\
1 \text { "Most people can be trusted" } \\
0 \text { "Need to be very careful" }\end{array}$ & \\
\hline Sex & 1 "Male", 0 "Female" & \\
\hline Age & In years & \\
\hline Education & $\begin{array}{l}\text { What is the highest educational level that you have } \\
\text { attained? } \\
1 \text { No formal education } \\
2 \text { Incomplete primary school } \\
3 \text { Complete primary school } \\
4 \text { Incomplete secondary school: technical/vocational type } \\
5 \text { Complete secondary school: technical/vocational type } \\
6 \text { Incomplete secondary: university-preparatory type } \\
7 \text { Complete secondary: university-preparatory type } \\
8 \text { Some university-level education, without degree } \\
9 \text { University-level education, with degree }\end{array}$ & \\
\hline
\end{tabular}


Table 7 continued

\begin{tabular}{|c|c|c|}
\hline Variables & Operationalization & Data Source \\
\hline Income & $\begin{array}{l}\text { On this card is a scale of incomes on which } \\
1 \text { indicates the "lowest income decile" and } \\
10 \text { the "highest income decile" } \\
\text { in your country. We would like to know in what group your } \\
\text { household is (sig!). Please, specify the appropriate } \\
\text { number, counting all wages, salaries, pensions and other } \\
\text { incomes that come in. }\end{array}$ & \\
\hline $\begin{array}{l}\text { Active } \\
\text { organizational } \\
\text { membership }\end{array}$ & $\begin{array}{l}\text { Now I am going to read off a list of voluntary } \\
\text { organizations. For each one, could you tell me whether } \\
\text { you are an active member, an inactive member or not a } \\
\text { member of that type of organization? } \\
\text { Church or religious, sport, recreational, art, music or } \\
\text { educational, labor union, political party, environmental, } \\
\text { professional association, humanitarian or charitable, } \\
\text { consumer organization, any other organization. } \\
0 \text { "inactive/no membership" } \\
1 \text { "active membership" }\end{array}$ & \\
\hline Happiness & $\begin{array}{l}\text { Taking all things together, would you say you are: } \\
1 \text { "Very happy" } \\
2 \text { "Rather happy" } \\
3 \text { "Not very happy" } \\
4 \text { "Not at all happy" }\end{array}$ & \\
\hline \multicolumn{3}{|l|}{ Context variables } \\
\hline Ethnic diversity & Herfindahl index, higher values indicating higher diversity & Fearon (2003) \\
\hline Income inequality & Gini-index, higher values indicating more inequality & World Bank 2004 \\
\hline $\begin{array}{l}\text { Gross Domestic } \\
\text { Product per } \\
\text { capita }\end{array}$ & $\begin{array}{l}\text { GDP per capita, PPP (current international \$) mean } \\
\text { 2000-2004 }\end{array}$ & $\begin{array}{l}\text { WDI/World Bank } \\
\text { 2000-2004 }\end{array}$ \\
\hline Democratization & Combined polity score & Polity IV Project \\
\hline Religious tradition & Dummy for protestant religious tradition & $\begin{array}{l}\text { Classification of religious } \\
\text { tradition from Inglehart } \\
\text { and Baker (2000) }\end{array}$ \\
\hline Stock of migrants & International stock of migrants in the country in 2005 & $\begin{array}{l}\text { World Bank development } \\
\text { indicators }\end{array}$ \\
\hline $\begin{array}{l}\text { Development of } \\
\text { stock of } \\
\text { migrants }\end{array}$ & International stock of migrants \% difference 1990-2005 & $\begin{array}{l}\text { World Bank development } \\
\text { indicators }\end{array}$ \\
\hline
\end{tabular}




\section{References}

Allport, G. W. (1954). The nature of prejudice. Cambridge, MA: Addison Wesley.

Anderson, C. J., \& Paskeviciute, A. (2006). How ethnic and linguistic heterogeneity influence the prospects for civil society: A comparative study of citizenship behavior. Journal of Politics, 68, 783-802.

Bahry, D., Kosolapov, M., Kozyreva, P., \& Wilson, R. K. (2005). Ethnicity and trust: Evidence from Russia. American Political Science Review, 99, 521-532.

Bjørnskov, C. (2008). Social trust and fractionalization: A possible reinterpretation. European Sociological Review, 24, 271-283.

Blau, P. M. (1977). Inequality and heterogeneity: A primitive theory of social structure. New York: Free Press.

Blumer, H. (1958). Race prejudice as a sense of group position. Pacific Sociological Review, 1, 3-7.

Brambor, T., Clark, W. R., \& Golder, M. (2006). Understanding interaction models: Improving empirical analyses. Political Analysis, 14, 63-82.

Cook, S. W. (1962). The systematic analysis of socially significant events: A strategy for social research. Journal of Social Issues, 18, 66-84.

Delhey, J., \& Newton, K. (2005). Predicting cross-national levels of social trust: Global pattern or nordic exceptionalism? European Sociological Review, 2, 311-327.

Delhey, J., Newton, K., \& Welzel, C. (2011). How general is trust in "most people"? Solving the radius of trust problem. American Sociological Review, 76, 786-807.

Dinesen, P Th. (2011). Me and Jasmina down by the schoolyard: An analysis of the impact of ethnic diversity in school on the trust of schoolchildren. Social Science Research, 40, 572-585.

Fearon, J. D. (2003). Ethnic and cultural diversity by country. Journal of Economic Growth, 8, 195-222.

Forbes, H. D. (1997). Ethnic conflict: Commerce, culture, and the contact hypothesis. New Haven [u.a.]: Yale University Press.

Freitag, M., \& Bauer, P. (2013). Testing for measurement equivalence in surveys: Dimensions of social trust across cultural contexts. Public Opinion Quarterly. doi:10.1093/poq/nfs064.

Freitag, M., \& Traunmüller, R. (2009). Spheres of trust: An empirical analysis of the foundations of particularised and generalised trust. European Journal of Political Research, 48, 782-803.

Fukuyama, F. (1995). Trust. New York: Free Press.

Gelman, A., \& Hill, J. (2007). Data analysis using regression and multilevel/hierarchical models. Cambridge: Cambridge University Press.

Gerritsen, D., \& Lubbers, M. (2010). Unknown is unloved? Diversity and inter-population trust in Europe. European Union Politics, 11, 267-287.

Gesthuizen, M., Van der Meer, T., \& Scheepers, P. (2008). Ethnic diversity and social capital in Europe: Tests of Putnam's thesis in European countries. Scandinavian Political Studies, 31, 1-22.

Gijsberts, M., Van der Meer, T., \& Dagevos, J. (2012). 'Hunkering down' in multi-ethnic neighbourhoods? The effects of ethnic diversity on dimensions of social cohesion. European Sociological Review, 28, 527-537.

Hooghe, M., Reeskens, T., Stolle, D., \& Trappers, A. (2009). Ethnic diversity and generalized trust in Europe: A cross-national multilevel study. Comparative Political Studies, 42, 198-223.

Huckfeldt, R. (1986). Politics in context: Assimilation and conflict in urban neighborhoods. New York: Agathon Press.

Huddy, L., Feldman, S., Taber, C., \& Lahav, G. (2005). Threat, anxiety, and support of antiterrorism policies. American Journal of Political Science, 49, 593-608.

Inglehart, R., \& Baker, W. E. (2000). Modernization, cultural change, and the persistence of traditional values. American Sociological Review, 65, 19-51.

King, G., Honaker, J., Joseph, A., \& Scheve, K. (2001). Analyzing incomplete political science data: An alternative algorithm for multiple imputation. American Political Science Review, 95, 49-70.

Lancee, B., \& Dronkers, J. (2011). Ethnic, religious and economic diversity in Dutch neighbourhoods: Explaining quality of contact with neighbours, trust in the neighbourhood and inter-ethnic trust. Journal of Ethnic and Migration Studies, 37, 597-618.

Laurence, J. (2011). The effect of ethnic diversity and community disadvantage on social cohesion: A multi-level analysis of social capital and interethnic relations in UK communities. European Sociological Review, 27, 70-89. 
Letki, N. (2008). Does diversity erode social cohesion? Social capital and race in British neighbourhoods. Political Studies, 56, 99-126.

Lolle, H., \& Torpe, L. (2011). Growing ethnic diversity and social trust in European societies. Comparative European Politics, 9, 191-216.

Marschall, M. J., \& Stolle, D. (2004). Race and the city: Neighborhood context and the development of generalized trust. Political Behavior, 26, 125-153.

McPherson, M., Smith-Lovin, L., \& Cook, J. M. (2001). Birds of a feather: Homophily in social networks. Annual Review of Sociology, 27, 415-444.

Öberg, P., Oskarsson, S., \& Svensson, T. (2011). Similarity vs. homogeneity: Contextual effects in explaining trust. European Political Science Review, 3, 345-369.

Offe, C. (1999). How can we trust our fellow citizens? In M. E. Warren (Ed.), Democracy and trust (pp. 42-87). Cambridge: Cambridge University Press.

Oliver, J. E., \& Wong, J. (2003). Intergroup prejudice in multiethnic settings. American Journal of Political Science, 47, 567-582.

Pettigrew, T. F. (1998). Intergroup contact theory. Annual reviews in psychology, 49, 65-85.

Putnam, R. D. (2007). E Pluribus Unum: Diversity and community in the twenty-first century. The 2006 Johan Skytte prize lecture. Scandinavian Political Studies, 30, 137-174.

Quillian, L. (1995). Prejudice as a response to perceived group threat: Population composition and antiimmigrant and racial prejudice in Europe. American Sociological Review, 60, 586-611.

Rubin, D. B. (1987). Multiple imputation for nonresponse in surveys. New York: Wiley.

Rudolph, T. J., \& Popp, E. (2010). Race environment, and interracial trust. The Journal of Politics, 72, 74-89.

Schlueter, E., \& Scheepers, P. (2010). The relationship between outgroup size and anti-outgroup attitudes: A theoretical synthesis and empirical test of group threat- and intergroup contact theory. Social Science Research, 39, 285-295.

Schlueter, E., \& Wagner, U. (2008). Regional differences matter. Examining the dual influence of the regional size of the immigrant population on derogation of immigrants in Europe. International Journal of Comparative Sociology, 49, 153-173.

Snijders, T. A. B., and Bosker, R. J. (2012). Multilevel analysis: An introduction to basic and advanced multilevel modeling. London [u.a.]: Sage.

Stolle, D. (2002). Trusting strangers-The concept of generalized trust in perspective. Österreichische Zeitschrift für Politikwissenschaft, 31, 397-412.

Stolle, D., Stuart, S., \& Johnston, R. (2008). When does diversity erode trust? Neighbourhood diversity, interpersonal trust, and the mediating effect of social interactions. Political Studies, 55, 57-75.

Sturgis, P., Brunton-Smith, I., Read, S., \& Allum, N. (2011). Does ethnic diversity erode trust?: Putnam's 'hunkering-down' thesis reconsidered. British Journal of Political Science, 41, 57-82.

Sturgis, P., \& Smith, P. (2010). Assessing the validity of the generalized trust question: What kind of trust are we measuring? International Journal of Public Opinion Research, 22, 74-92.

Tolsma, J., van der Meer, T., \& Gesthuizen, M. (2009). The impact of neighbourhood and municipality characteristics on social cohesion in the Netherlands. Acta Politica, 44, 286-313.

Torpe, L., \& Lolle, H. (2011). Identifying social trust in cross-country analysis: Do we really measure the same? Social Indicators Research, 103, 481-500.

Tsai, M.-C., Laczko, L., \& Bjørnskov, C. (2010). Social diversity, institutions and trust: A cross-national analysis. Social Indicators Research, 101, 305-322.

Uslaner, E. M. (2002). The moral foundations of trust. Cambridge: Cambridge University Press.

Uslaner, E. M. (2012). Segregation and mistrust. Diversity, isolation, and social cohesion. Cambridge: Cambridge University Press.

Uslaner, E. M., \& Brown, M. (2005). Inequality, trust, and civic engagement. American Politics Research, 33, 868-894.

Wagner, U., Christ, O., Pettigrew, T. F., Stellmacher, J., \& Wolf, C. (2006). Prejudice and minority proportion: Contact instead of threat effects. Social Psychology Quarterly, 69, 380-390. 